\title{
The Control of Blast Furnace Top Gas Pressure by using Fuzzy PID
}

\author{
Özgür Aslan, Aytaç Altan, Rıfat Hacıoğlu
}

\begin{abstract}
Blast furnace top gas pressure control is very important for the efficiency of the blast furnace process in iron and steel industry. In automation systems, the blast furnace top gas pressure control is performed by the PID algorithm which sends the reference signal to the proportional valve in the field. The variability of blast furnace process parameters and disturbances of the system decrease the control performance of PID algorithm. The pressure control system has higher overshoots and steady state errors. In this study, the model of the blast furnace top gas pressure control process is obtained by linear Auto-Regressive eXogenous (ARX) model structure. PID controller whose coefficients are determined by a fuzzy logic controller applied to ARX model of blast furnace top gas pressure control system. The performance of the PID and the fuzzy PID controllers compared.
\end{abstract}

Keywords - blast furnace, top gas pressure, ARX, Fuzzy PID, iron and steel industry.

\section{Introduction}

A blast furnace is the primary unit process in the world for reduction and melting iron ores [1]. Blast furnaces are reactors that produce liquid pig iron and slag at approximately 1450 degrees Celsius from iron ore (pellet, sinter), auxiliary materials, coke and pressurized hot air (hot blast air) [2]. Row materials are charged into the blast furnace from the top and hot air at about 1200 degrees Celsius is applied to the furnace base. As hot blast air goes up in the furnace, it reacts with the materials and heats these materials. These hot blast air turn into blast furnace gas after rise through the materials and escape from the top of the furnace [3]. At the bottom of the furnace, iron and slag liquefy by the heat. Hot blast air turn into pressurized blast furnace gas at the top after reacting with raw materials.

Özgür Aslan

Bülent Ecevit University

Turkey

Aytaç Altan

Bülent Ecevit University

Turkey

Rifat Hacıoğlu

Bülent Ecevit University

Turkey
For smooth and stable furnace operation the top gas pressure must be controlled and held as constant as possible [4]. If the top gas pressure is higher than the desired value, it will prevent hot air from moving upward in the furnace. Because of sudden pressure drop, the hot blast air suddenly move upwards and this movement cause the layers of materials in the furnace mix with each other and cause unwanted reactions in the furnace. Similarly, when the blast furnace top gas pressure is lower than the desired value the reduction process becomes inefficient and the iron production goes down.

For these reasons, the control of the blast furnace top gas pressure without any sudden changes is very important for the iron making process. There are some problems with controlling blast furnace top gas pressure with conventional PID controllers. The PID controller, which has slow response, does not react immediately to sudden pressure fluctuations and causes desired top gas pressure value not to be tracked. Quick response PID controllers also respond quickly to disturbance but cause the top gas pressure to reach undesirable values because of high overshoot degree.

In this study, we will examine the use of a fuzzy PID controller on blast furnace top gas pressure control. The P, I and D parameters of the fuzzy PID controller are determined according to the amount of process error. It is intended that when the error is higher the response of the PID controller is faster and the response of the PID controller is slower when the error is lower. Thus, it will be possible to provide blast furnace top gas pressure control with a controller that adapts itself according to the online error condition.

This article is organized as follows: the design and modelling of blast furnace top gas pressure control system is described in Section II. The Fuzzy PID controller of blast furnace top gas pressure control system is expressed in Section III. Simulation and experimental results are presented in Section IV. Conclusion and discussion are finally given in Section V.

\section{Blast Furnace Top Gas Pressure Control System Design and Modeling}

Blast furnace top gas pressure control is one of the most important stages of the iron making process. The blast furnace top gas pressure control is performed with proportional valves and actuators. When the valve closed, the blast furnace gas pipe becomes clogged and the pressure of the gas increases or 
vice versa. The operating principle of the blast furnace plant is shown in Figure 1.

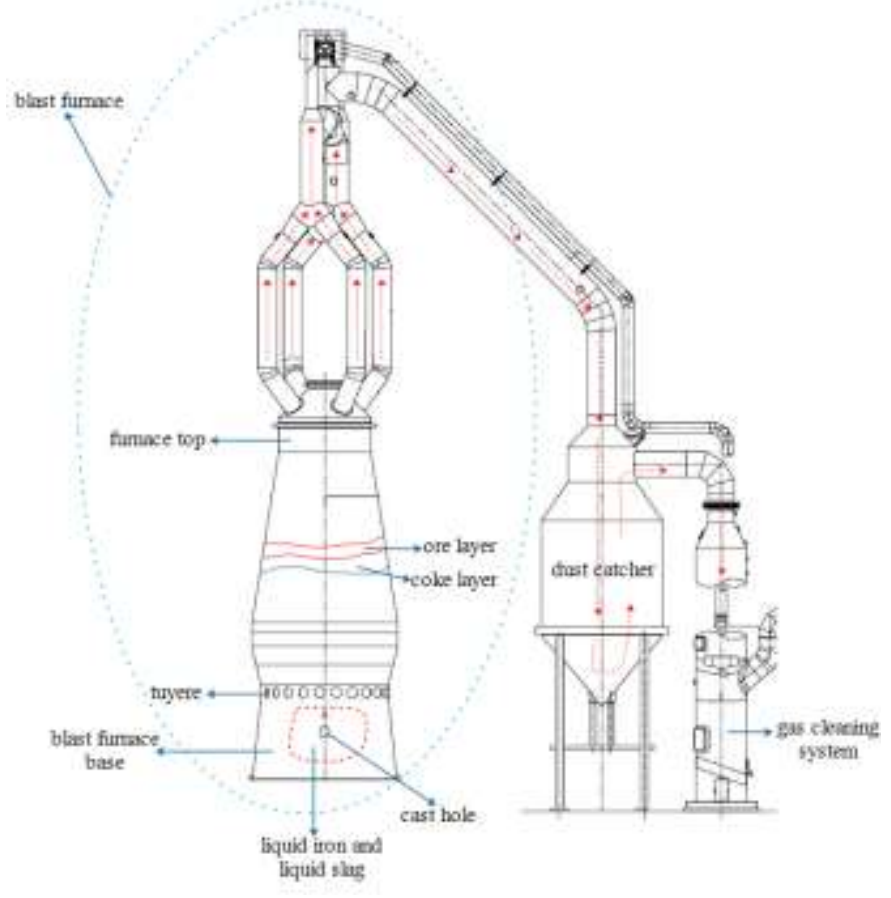

Figure 1. Blast furnace plant.

\section{A. Blast Furnace Top Gas Pressure Control Actuator}

Blast furnace is the first and often most critical step in the manufacture of iron and steel. A blast furnace consists of a large, vertical, cylindrical shaft furnace [5, 6]. The blast furnace top gas pressure control actuator in blast furnace plant to be investigated in the study is shown in Figure 2.

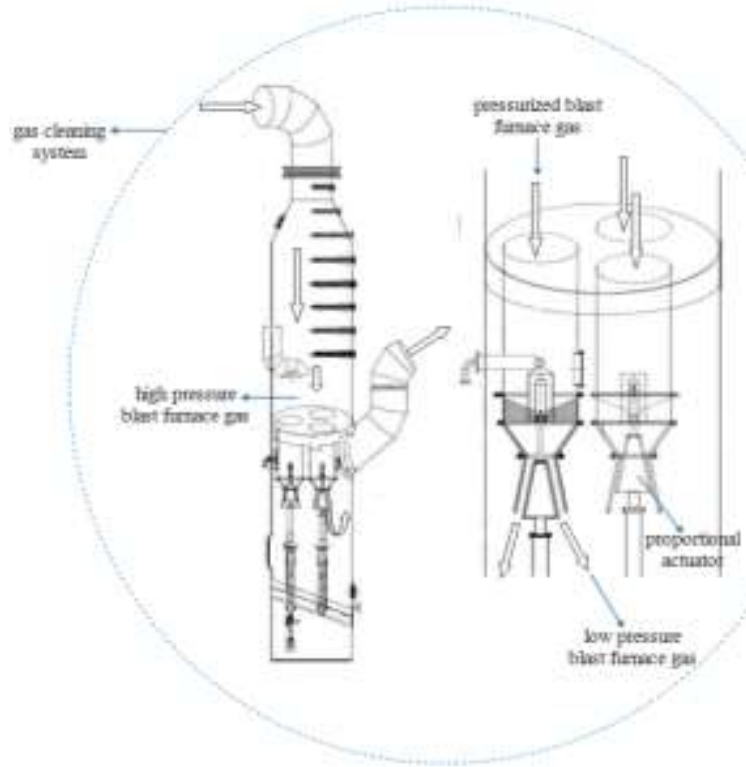

Figure 2. Blast furnace top gas pressure control actuator.
The pressurized blast furnace gas, which is free of dust in the gas holder and gas washer, passes through the three cylindrical gaps shown in the Figure 2 and goes to the low pressure pipeline. The amount of gas passing through the cylindrical gaps is adjusted by reducing and increasing the amount of funnel attached to the hydraulic pistons and the gas line pressure on the side of the blast furnace is adjusted.

\section{B. Identification ARX Model for Blast Furnace Top Gas Pressure Control System}

System identification is a method of obtaining mathematical model with statistical methods using experimental study for a dynamic system based on input/output data [7]. When the gain and dynamic behavior of system need to be determined, modeling is becomes quite important. Discrete time system models are often used. In this study, discrete time linear Auto-Regressive eXogenous (ARX) model structure is realized together with system identification problem.

The systems defined by the ARX model structure have linear properties [7] thus the blast furnace top gas pressure system which used in the study can be defined using ARX model structure. The block diagram of single input single output (SISO) linear system identification problem is shown in Figure 3.

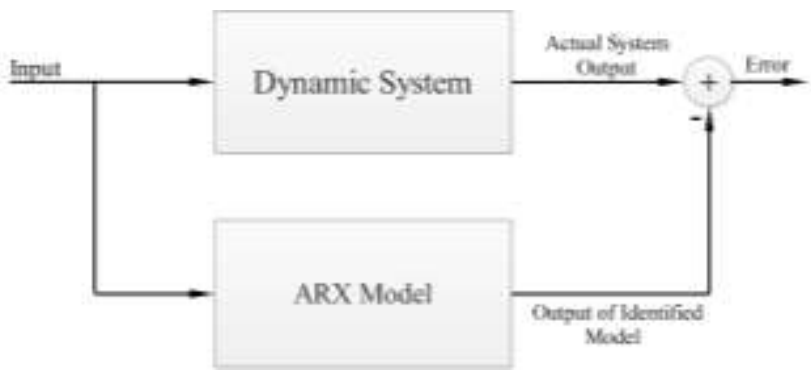

Figure 3. ARX model aproach of SISO linear system.

ARX, Auto Regressive Moving Average with eXogeneous (ARMAX), Auto Regressive Moving Average (ARMA), BoxJenkins (BJ) and Output Error (OE) are widely used parametric model structures for linear dynamic systems. The system dynamics are usually evaluated as a linear or nonlinear structure with black box, gray box, or physical modeling based on system pre-information [7]. The basic standard and statistical techniques which are least squares, recursive least squares and cumulative least squares methods are used in parameter estimation [8].

The transfer function is expressed by ARX model such as

$H\left(q^{-1}\right)=\frac{\sum_{k=0}^{M} b_{k} q^{-k}}{1+\sum_{k=1}^{N} a_{k} q^{-k}}$ 
where $q^{-1}$ is the delay operator, $a_{k}$ and $b_{k}$ are denominator and numerator polynomial coefficients, respectively. The output, $y(n)$ obtained depending on the input, $x(n)$ as follows difference equation:

$$
y(n)=-\sum_{k=1}^{N} a_{k} y(n-k)+\sum_{k=0}^{M} b_{k} x(n-k)
$$

In this study, ARX model structure parameters $a_{k}$ and $b_{k}$ are obtained by least squares method. Here it is minimized error between actual system output and output of the identified model for given same input in the least squared sense as seen in Figure 3.

\section{Fuzzy PID Control of Blast Furnace Top Gas Pressure}

Fuzzy logic is a control method that has become widespread in recent years. It is a control method based on the principle of converting to algorithmic and mathematical expressions that have verbal equivalents but not mathematical equivalents [9]. The parameters of PID controllers can be made variable using fuzzy controllers. In a closed-loop control system if the error value is high, it is desired that the PID controller quickly react to reduce the amount of error immediately. Similarly, when the amount of error is small, the PID controller must react slowly. Otherwise, the system may oscillate undesirably.

PID controllers used in automation systems are adjusted by engineers using methods such as Ziegler-Nicholes and heuristic tests. PID controllers that perform successfully under the conditions which they are tuned do not adapt with changes in process parameters or disturbances, and control performance decrease. Similarly, the error amount, which is the difference between the set value and the process value, is larger than when the PID tuning is made, which leads to an increase in the system rise and settling time values.

Adaptation of the PID controller according to different situations allows the control performance to be improved. In cases where the error value is small, the PID controller should react slowly. Thus, the rise and settling times increase but these delays can also be neglected since the amount of error is already within acceptable limits. In other cases where the error value is large, the PID controller should react quickly. The reference form the PID controller output changes quickly and results reduced rising time. In response to the sudden varying reference value, the amount of recovered process error is reduced faster and the PID controller slows down again to decrease the maximum overshoot and settling time.

In this study, we created the ARX model of blast furnace top gas pressure control system to use it as a simulation environment for fuzzy PID control. For the ARX model, two separate PID parameter sets with fast and slow responses were determined. The control of a real blast furnace top gas pressure with the PID controllers that created with these parameters is not even possible due to the actual system disturbances. The slow behavior controller will react slowly to the effect of sudden disturbance and will not prevent the top gas pressure from increasing or decreasing. Otherwise, the fast behavior controller will react quickly to sudden disruptive effects. However, when the blast furnace system is stabilized, it will cause undesirable fluctuations in the top gas pressure.

The fuzzy logic PID controller, which automatically adjusts itself to the closed-loop fault, is designed using the upper and lower limits specified for the PID controllers in the blast furnace top gas pressure control. Three input membership functions were defined as "negative high", "low" and "positive high" depending on the amount of closed loop error. The input membership functions of the fuzzy controller are shown in Figure 4. The fuzzy logic controller has 3 outputs. These outputs define the P, I, and D parameters of the PID controller that will control the blast furnace top gas pressure. These outputs are based on two membership functions called "slow" and "fast", as shown in Figure 5, depending on whether the error value is large or small.

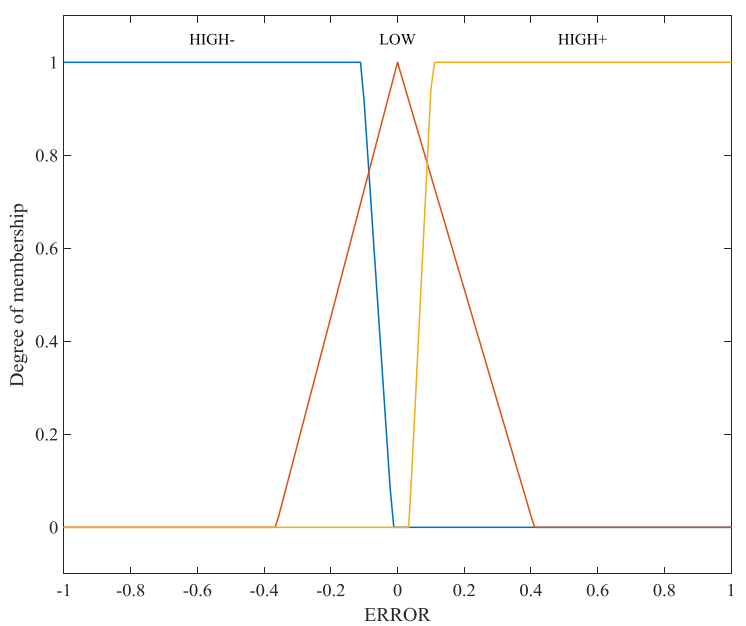

Figure 4. Fuzzy logic controller input membership functions.
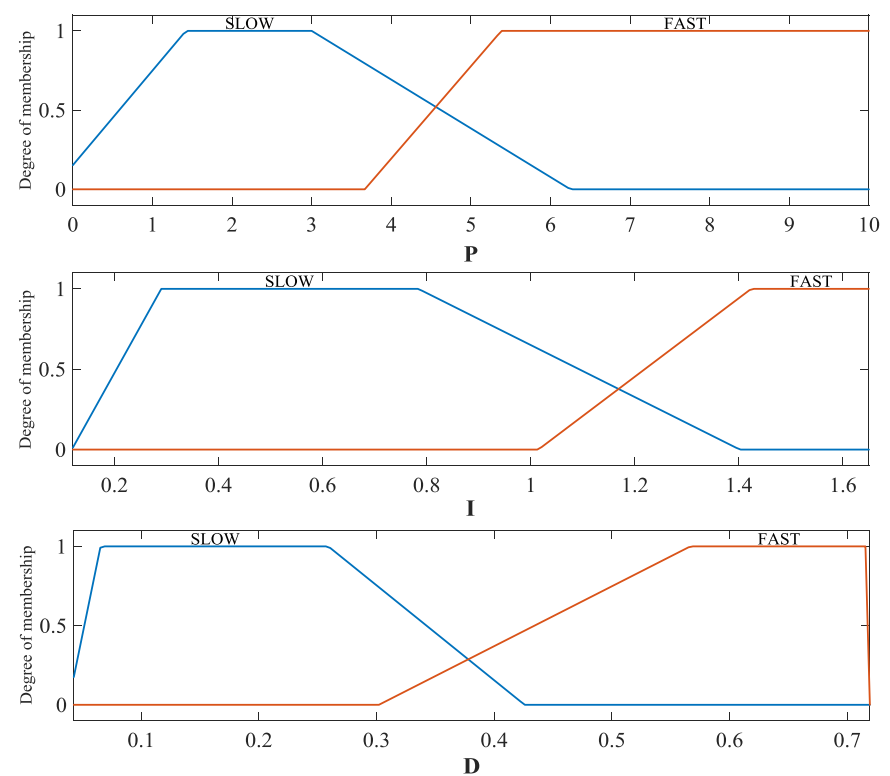

Figure 5. Fuzzy logic controller output membership functions. 


\section{Simulation and Experimental Results}

In this study, the following transfer function of ARX Model, which is obtained by system identification method, is used in simulation.

$H(z)=\frac{0.0128}{z^{2}-1.2143 z+0.3197}$

The same reference input signal is applied to 3 separate closed loop system systems obtained with ARX Model. These closed-loop systems are controlled by two separate PID controllers which are set to fast and slow response and a Fuzzy PID controller.

In the simulation environment is shown in Figure 6, the output of three separate systems is first fixed to $1.2 \mathrm{~kg} / \mathrm{cm}^{2}$, which is the top gas pressure value of the blast furnace under normal operating conditions. Subsequently, the reference input signal (set point of the blast furnace top gas pressure) is increased by $0.2 \mathrm{~kg} / \mathrm{cm}^{2}$, enabling the controllers to increase the system outputs to $1.4 \mathrm{~kg} / \mathrm{cm}^{2}$. The simulation results are shown in Figure 7.

For the system controlled by the Fuzzy PID controller, the rise time was measured as $1.6 \mathrm{~s}$, the settling time was $11.1 \mathrm{~s}$ and the overshoot value was measured as $8.5 \%$. For the fast response PID controller, the rise time was $1.7 \mathrm{~s}$, the settling time was $10 \mathrm{~s}$, and the overshoot value was $23.4 \%$. For the slow response PID controller, the rise time was $8.9 \mathrm{~s}$, the settling time was 16s, and the overshoot was $8 \%$.

According to the Figure 7 and the rise time and settling time values, the fast response PID controller and the Fuzzy PID controller are closer. However, higher overshoot value of the fast response PID controller is caused unwanted sudden pressure differences in the blast furnace process. Although the slow response PID controller solves the high overshoot value problem, the rise and settling time values achieved with this controller are very high. This shows that with the slow response controller, the desired blast furnace top gas pressure will be reached slowly.

In the 50th second of the simulation, where process values are equal for the three systems, the system reference inputs are increased from $1.2 \mathrm{~kg} / \mathrm{cm}^{2}$ to $1.4 \mathrm{~kg} / \mathrm{cm}^{2}$. Thus, the error in the system increased to $0.2 \mathrm{~kg} / \mathrm{cm}^{2}$. According to Figure 4, for 0.2 $\mathrm{kg} / \mathrm{cm}^{2}$ of error, membership degree of the "positive high" membership function is bigger than "low" membership function. The fuzzy PID controller, which is automatically tuned with referenced to the error value, quickly reacted. During the 50th and 51st seconds of the simulation, the fuzzy PID controlled system response is the fastest one. Since the error value decreased, membership degree of the "positive high" membership function started to decrease and the degree of the "low" membership function started to increase. Therefore the speed of Fuzzy PID decreased. When the error fell below 0.1 in the 51st second, the membership degree of the "low" membership function further increased, causing the PID controller speed to decelerate significantly. After the 52nd second the Fuzzy PID controller was slower than the fast PID controller, but it ensured that the overshoot value in the system to be lower.

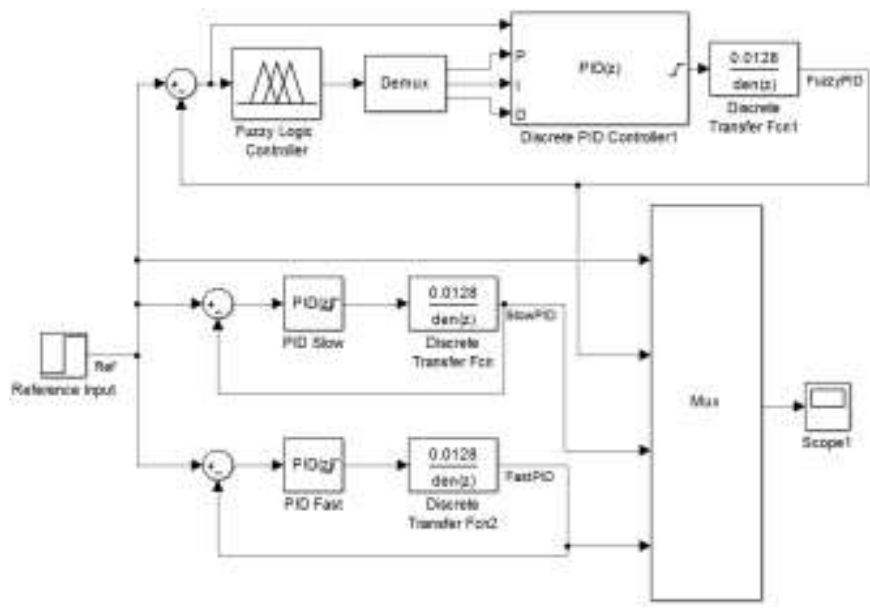

Figure 6. Fuzzy control simulation of blast furnace top gas pressure system.

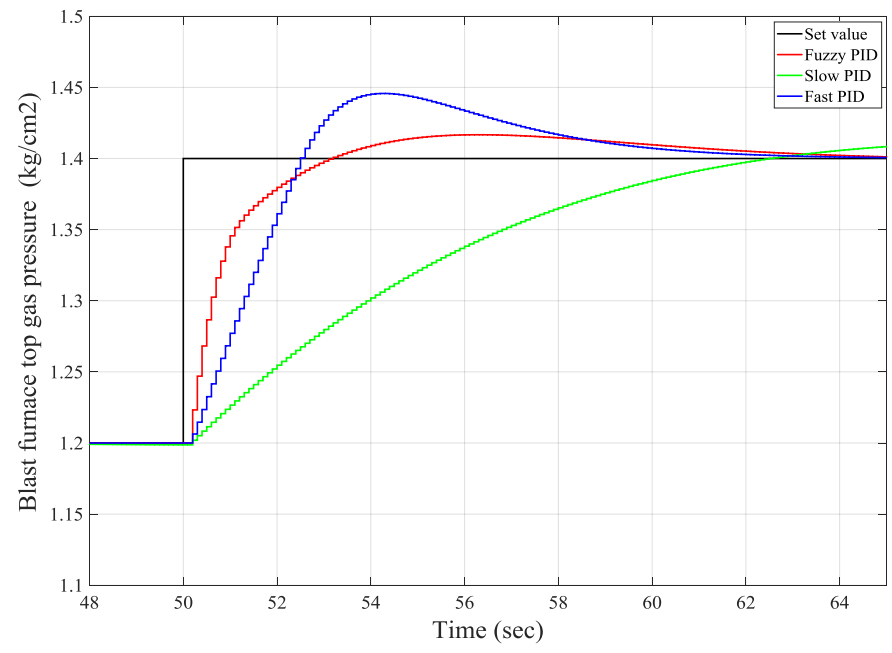

Figure 7. Fuzzy PID vs PID control of blast furnace top gas pressure system.

\section{v. Conclusion and Discussion}

Linear ARX Model was created with input-output data from blast furnace top gas pressure control process. Simulation of the blast furnace top gas pressure control was performed using PID controllers with different response times and fuzzy PID controller. The simulation results show that the fuzzy logic PID controller has higher performance in the blast furnace top gas pressure control. The parameters of PID controllers used in blast furnace automation systems are determined by conventional methods. Due to the fact that P, I, D parameters are constant, PID controller performance drops with varying conditions. The parameters of the existing PID controllers used in the blast furnace automation system can be determined by fuzzy logic controllers. The PID controllers whose parameters are determined by fuzzy logic controller, 
will improve the control performance as adapting to variable conditions.

\section{References}

[1] H. Helle, M. Helle, and H. Saxen, "Nonlinear optimization of steel production using traditional and novel blast furnace operation strategies," Chemical Engr. Sci., vol. 66(24), pp. 6470-6481, December 2011.

[2] A. Jindal, S. Pujari, P. Sandilya, and S. Ganguly, "A reduced order thermo-chemical model for blast furnace for real time simulation," Computers and Chemical Engineering, vol. 31(11), pp. 1484-1495, November 2007.

[3] Z. Y. Zhou, H. P. Zhu, A. B. Yu, B. Wright, and P. Zulli, "Discrete particle simulation of gas-solid flow in a blast furnace," Computers and Chemical Engineering, vol. 32(8), pp. 1760-1772, August 2008.

[4] A. Lajtonyi, "Blast furnace gas cleaning systems," Millennium Steel, pp. $57-65,2006$.

[5] V. R. Radhakrishnan and A. R. Mohamed, "Neural networks for the identification and control of blast furnace hot metal quality," J. Process Control, vol. 10(6), pp. 509-524, December, 2000.

[6] Ö. Aslan, Model predictive controller applications based on linear and nonlinear model structures in iron steel industry, M.Sc. Thesis, Zonguldak, 2009

[7] L. Ljung, System Identification: Theory for the User. Prentice Hall, New Jersey, 1999.

[8] G. Wang, T. Li, G. Zhang, X. Gui, and D. Xu, "Position estimation error reduction using recursive-least-square adaptive filter for model-based sensorless interior permanent-magnet synchronous motor drives," IEEE Trans. Ind. Elect., vol. 61(9), pp. 5115-5125, September 2014.

[9] J. Godjevac, "Comparison between PID and fuzzy control," Internal Report R93.36I, LAMI IN F EPFL Ecublens, pp. 25-36, 2000.

About Authors:

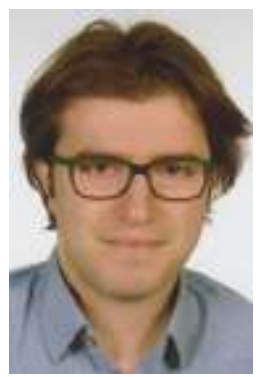

Özgür Aslan works as an automation engineer at Erdemir Iron and Steel factory. He received the BSc and M.Sc. degrees in the department of Electrical Electronics Engineering from Zonguldak Karaelmas University in 2006 and 2009, respectively. $\mathrm{He}$ is a $\mathrm{Ph} . \mathrm{D}$. candidate at BEU. His research interests are automation systems, adaptive control, fuzzy logic and system identification.

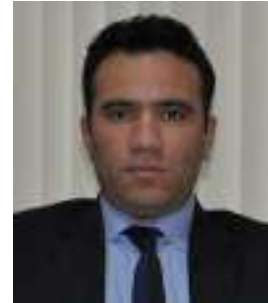

Aytaç Altan is a lecturer at the department of Electrical Electronics Engineering, Bulent Ecevit University in Turkey. He received the BSc and M.Sc. degrees in the department of Electrical Electronics Engineering from Anadolu University in 2011 and 2016, respectively. $\mathrm{He}$ is a Ph.D. candidate. His research interests are robotic systems, adaptive control and system identification.

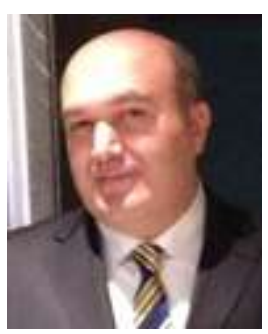

Rifat Hacıoğlu is an Assistant Professor of department of Electrical Electronics Engineering at the Bulent Ecevit University in Turkey. $\mathrm{He}$ received the M.Sc. and Ph.D. degrees in the department of Electrical Electronics Engineering from Illinois Institute of Technology in 1996 and 2002, respectively. His research interests are signal processing, control applications, linear and nonlinear system identification, parametric model estimation approaches, microprocessor based control systems, image identification problems. 